\section{CONTROLLED HYPOTHERMIA}

\section{RECENT DEVELOPMENTS IN THE USE OF HYPOTHERMIA IN NEUROSURGERY}

\author{
BY
}

PAMELA M. HELLINGS, M.B., F.F.A. R.C.S. Recently Research Anaesthetist to the Neurosurgical Unit of St. George's Hospital, London

Hypothermia is a technique of comparatively recent application, and may be described as a method of reducing the normal body temperature of the whole patient. The method was first practised by Smith and Fay (1939) in the attempted treatment of neoplasms, with a view to slowing the rate of tumour growth at lowered temperatures.

More recently McQuiston (1949) used hypothermia during cardiac surgery carried out on hypoxaemic children. Further interest was taken in this when Bigelow et al. (1950) suggested that the lowered oxygen demand of the brain during hypothermia would protect it against ischaemia during intracardiac operations. Since then the method has been used extensively as an aid to cardiac surgery.

The application of hypothermia to neurosurgical conditions is of more recent origin. Rosomoff and Gilbert (1955) noted a reduced brain volume when experimenting with dogs under hypothermia, and accordingly recommended its use in neurosurgery. Lougheed et al. (1955) followed with a report on two cases in which hypothermia had been used for the surgical treatment of vascular lesions, and Botterell et al. (1956) reported on the use of hypothermia in the management of 22 cases of intracranial aneurysms.

\section{The Investigation}

Thus the value of hypothermia in the treatment of neurosurgical conditions had been established on a broad basis by the end of 1956, when work was begun with a view to developing a practical and routine method for use with a busy neurosurgical unit.

From November, 1956, until December, 1957, 123 patients whose ages ranged from 6 to 78 years were treated under hypothermia. This paper shows how the routine method was evolved and established.

At the outset an unselected series of ruptured intracranial aneurysms and angiomas were treated surgically under hypothermia ; later, when it became evident that the method was safe and the value of the improved operating conditions was appreciated, confidence grew, and the method was used

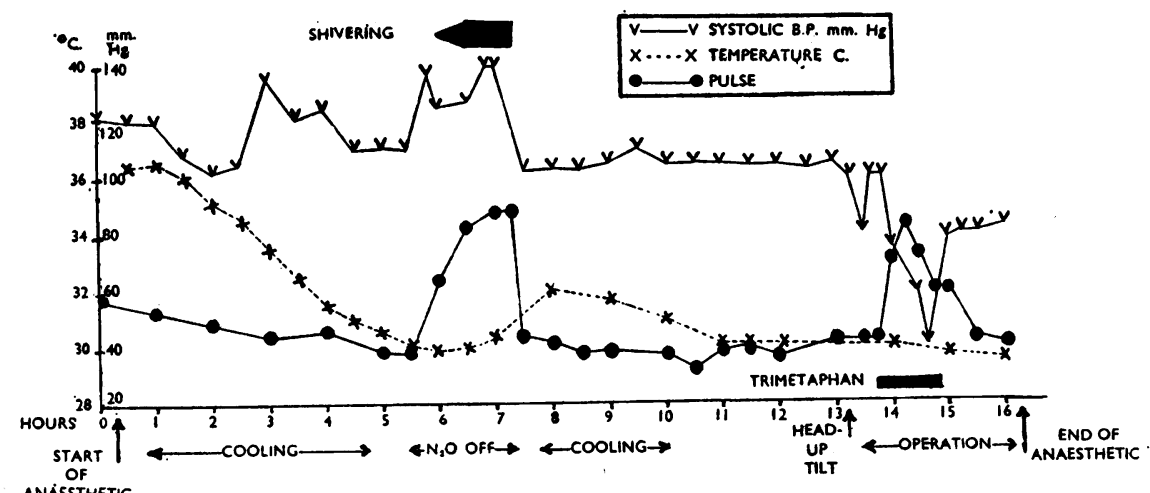

Fig. 1-Chart of Case 6. during other intracranial procedures, particularly for meningiomas.

The danger of repeated subarachnoid haemorrhage in cases of ruptured intracranial aneurysms is well known. Thus to avoid a further bleed before operative treatment could be carried out, and also in the hope that the patient's condition might improve, the first five cases in this series were cooled over a period of 5 to 19 hours, using the "lytic cocktail" combined with sodium amylobarbitone to prevent shivering. Fans played upon the patient continuously and body surfaces were kept constantly moist with a dilute solution of cetrimide in water, the former being added to reduce surface tension, thus allowing a film of moisture to remain on the skin for a longer period than would water alone. At the time chosen for operation the temperature lay between 30 and $31^{\circ} \mathrm{C}$., and a general anaesthetic was then given. This was discontinued at the end of the operation, when warming was begun with electrically heated blankets. This method has the following disadvantages :

1. Shivering occurred even though large amounts of drugs were administered. In one case $180 \mathrm{mg}$. of chlorpromazine, $100 \mathrm{mg}$. of promethazine hydrochloride, $190 \mathrm{mg}$. of pethidine, and $900 \mathrm{mg}$. of sodium amylobarbitone were given and slight shivering was still present, which increased if the patient was moved or disturbed in any way. Rosomoff and Gilbert (1955) pointed out the need for adequate anaesthesia in these cases because of the rise in C.S.F. pressure which occurs with shivering.

2. As a result of the large quantities of drugs administered the blood pressure was not easy to control. A steep drop in blood pressure was apt to occur on moving the patient, on tilting to a head-up position, and again after only a small blood loss. This fall was not compensated for immediately, and the blood pressure tended to remain low for long periods. This reduced blood flow to the already damaged brain, which, even though the temperature was low and the tissue oxygen requirements were diminished, might well have proved to be insufficient. There was also considerable danger of cerebral thrombosis if the blood pressure remained low for any length of time.

3. The fall in temperature was difficult to control, and a further fall tended to occur after induction of general anaesthesia.

In view of the foregoing difficulties it was decided to take advantage of the strong anti-shivering action of nitrous oxide, as described subsequently by Parkhouse (1957).

Accordingly the sixth case in the series-a ruptured intracranial aneurysm-was treated by hypothermia under prolonged general anaesthesia. When the temperature had reached the required level the nitrous oxide was discontinued, and the effect of this, together with its reintroduction, is illustrated in Fig. 1. The pulse rate rose, and the blood pressure rose steeply as shivering became more marked, and both settled dramatically to their former level when the nitrous oxide was reintroduced. A slow rise in temperature occurred later as a result of the increased heat production on shivering, and further cooling was necessary to reduce the temperature to the required level again. Intravenous drugs were given during the initial cooling process-thiopentone 250 mg., pethidine $60 \mathrm{mg}$., " tubarine" 30 mg., sodium amylobarbitone $500 \mathrm{mg}$. in all were given. No further drugs were needed to prevent shivering after reintroducing nitrous oxide.

This case was of interest because the patient had undergone haemorrhage from a ruptured posterior cerebral aneurysm on four separate occasions during the three weeks prior to admission to hospital, the last haemorrhage 
occurring within the 24 hours before admission. Further rupture was prevented by ligation of the neck of the aneurysm at operation, and the patient eventually made a complete recovery.

It became evident that the advantage of prolonged hypothermia, preventing further haemorrhage, did not outweigh the disadvantages of prolonged anaesthesia, and therefore the remaining cases were operated upon as soon as the temperature had been reduced to the required level under general anaesthesia.

The following method of producing a state of hypothermia at a temperature level between 31 and $30^{\circ} \mathrm{C}$. was used for the remaining 117 cases.

\section{Procedure}

\section{Anaesthesia}

The patient was given promethazine, pethidine, and atropine as premedication. One hour later anaesthesia was induced with thiopentone, suxamethonium, and pethidine, and was maintained with nitrous oxide and oxygen, together with additional doses of pethidine and thiopentone. If this proved insufficient to prevent shivering, suxamethonium was given in repeated intravenous injections, or, alternatively, tubarine was given in small doses until shivering was controlled. Respirations were aided or controlled as required.

\section{Hypothermia}

Hypothermia was effected by means of surface cooling, using ice, after the induction of anaesthesia. Ice packs were placed above and below the trunk of the patient, and also

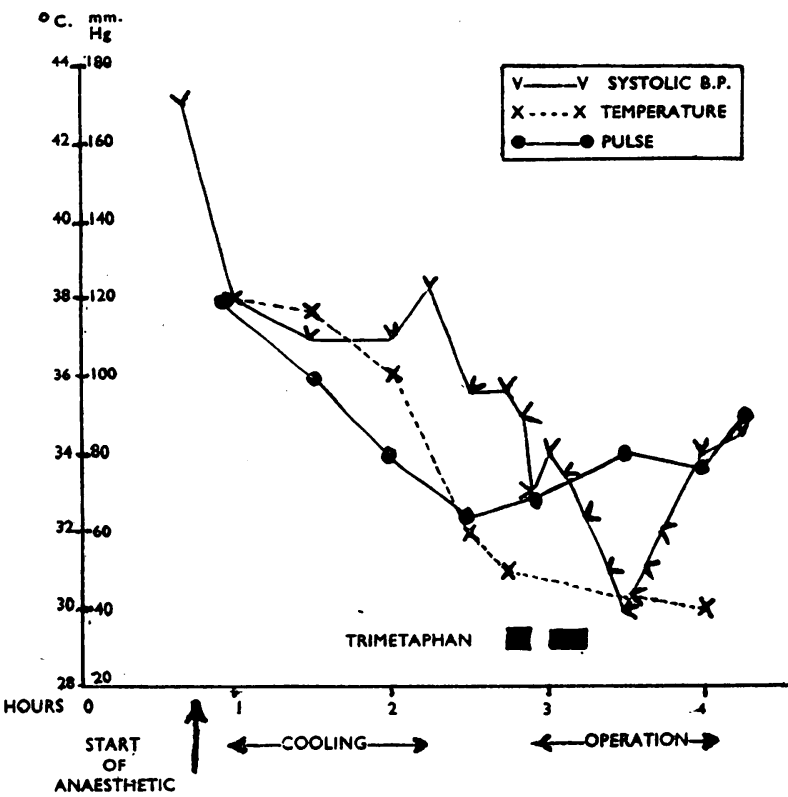

Fig. 2.-Chart of a thin patient (approximate weight, $57 \mathrm{~kg}$.).

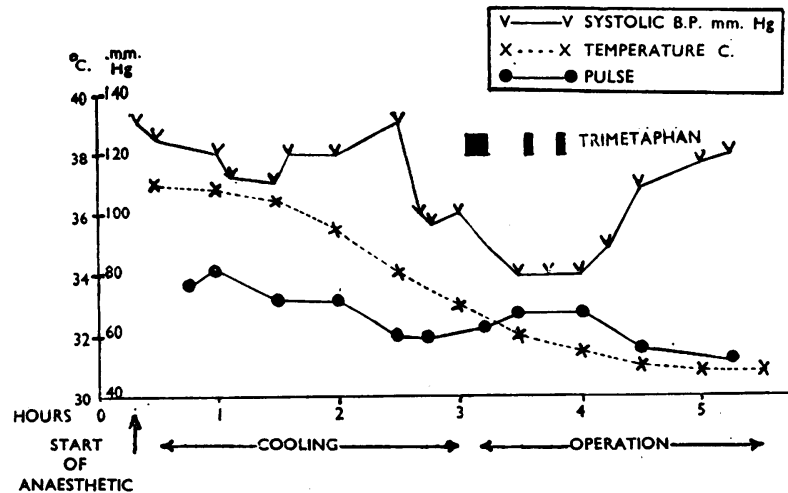

Fi6. 3.-Chart of an obese patient (approximate weight, $73 \mathrm{~kg}$.). over the large arteries which run near the surface of the skin - that is, the carotid, femoral, and axillary arteries. In order to avoid too great a drop in their temperature the limbs were not cooled directly. The skin in contact with the ice packs was massaged at frequent intervals to assist the circulation of the cooled blood; this was of particular value in the case of the obese patient, as it reduced the temperature gradient between the centre and the surface of the body.

The main difficulty was to obtain toleration of the cold applied without depressing the vital centres or producing apnoea by giving large doses of relaxants: the temperature of the surroundings was found to be of little importance when ice was used, provided the ice was replaced as it melted. As the blood supply to the damaged brain had already been reduced by spasm of the supplying vessels, and would be further reduced by hypotension, care was taken not to depress the blood pressure until this was required during operation. Apnoea was produced during the process of cooling in those cases where relaxants were necessary to control shivering, but it was essential to ensure that respirations were present during the neurosurgical procedure, as a guide to the surgeon.

The ice packs were removed at $33-32^{\circ} \mathrm{C}$, and the patient was then ready for operation. Before the main part of the operation had been completed the temperature had continued to fall to $31-30^{\circ} \mathrm{C}, 30^{\circ} \mathrm{C}$. being the lowest temperature level required.

This further drop in temperature after the removal of the ice occurred more quickly and to a lower degree in the thin patient than in the obese, because of the insulating effect of fat against cold. Hence the steeper the fall in temperature during cooling the greater the "after-drop" expected. Thus when a thin patient was cooled rapidly the ice had to be removed at between 34 and $33^{\circ} \mathrm{C}$. to avoid too profound a final drop in temperature. This point is illustrated in Figs. 2 and 3.

\section{Temperatures}

Rate of Temperature Fall.-When hypothermia was produced by the method described, the time taken for the temperature to fall was proportional to the weight and surface area of the patient. As a rough guide, the time taken for the temperature to fall from normal to $33^{\circ} \mathrm{C}$. (when the ice was removed) was calculated on the basis of one hour per 6 stone $(38 \mathrm{~kg}$.) weight. Thus a 12-stone (76-kg.) patient would take approximately two hours, the time varying slightly according to the patient's surface area - that is, the tall and thin would take a relatively shorter period than shorter patients of the same weight.

Temperatures were recorded from the rectum and from the nasopharynx, using glass alcohol thermometers. In 28 cases the brain temperature was also recorded during operation, and Table I shows the variable degree of correlation of the rectal temperature compared with the brain temperature.

Nasopharyngeal temperatures were not recorded during operation, as access to the nose, using glass thermometers, was impossible.

TARLE I

\begin{tabular}{|c|c|c|c|c|c|c|c|}
\hline \multirow{2}{*}{$\begin{array}{l}\text { Case } \\
\text { No. }\end{array}$} & \multirow{2}{*}{$\begin{array}{l}\text { Weight } \\
\text { in Kg. }\end{array}$} & \multicolumn{2}{|c|}{ Temperature $\left({ }^{\circ} \mathrm{C}.\right)$} & \multirow{2}{*}{$\begin{array}{l}\text { Case } \\
\text { No. }\end{array}$} & \multirow{2}{*}{$\begin{array}{l}\text { Weight } \\
\text { in Kg. }\end{array}$} & \multicolumn{2}{|c|}{ Temperature $\left({ }^{\circ} \mathrm{C}.\right)$} \\
\hline & & Rectal & Brain & & & Rectal & Brain \\
\hline $\begin{array}{r}1 \\
2 \\
3 \\
4 \\
5 \\
6 \\
7 \\
8 \\
9 \\
10 \\
11 \\
12 \\
13 \\
14\end{array}$ & $\begin{array}{r}63 \\
94 \\
63 \\
63 \\
63 \\
70 \\
50 \\
60 \\
111 \\
63 \\
79 \\
94 \\
57 \\
.63\end{array}$ & $\begin{array}{l}32 \\
31.6 \\
29.5 \\
32 . \\
31.5 \\
29.4 \\
30.5 \\
31.2 \\
35.2 \\
31 \\
31 \\
32.5 \\
30.7 \\
30.5\end{array}$ & $\begin{array}{l}32.2 \\
30.7 \\
30.1 \\
29.8 \\
29.6 \\
29.2 \\
28.9 \\
30.9 \\
33.1 \\
29.2 \\
30.9 \\
31.4 \\
30 \\
30.2\end{array}$ & $\begin{array}{l}15 \\
16 \\
17 \\
18 \\
19 \\
20 \\
21 \\
22 \\
23 \\
24 \\
25 \\
26 \\
27 \\
28\end{array}$ & $\begin{array}{l}67 \\
82 \\
63 \\
57 \\
57 \\
60 \\
82 \\
70 \\
63 \\
50 \\
63 \\
63 \\
63 \\
57\end{array}$ & $\begin{array}{l}31.4 \\
31.4 \\
31.2 \\
31 \\
30.4 \\
31.2 \\
32.5 \\
30.5 \\
29 \\
30.9 \\
33 \\
34.3 \\
30.8 \\
30.4\end{array}$ & $\begin{array}{l}29.4 \\
29.4 \\
29.8 \\
28.9 \\
31.2 \\
30 \\
30 \\
29.5 \\
28.9 \\
29.1 \\
30.4 \\
33.1 \\
30.4 \\
29.8\end{array}$ \\
\hline
\end{tabular}




\section{Warming}

At the end of the operation anaesthesia was discontinued, and no active attempts were made to rewarm the patient unless the temperature tended to drop post-operatively. Normal temperatures were usually regained within eight hours of the operation. Promethazine was given to reduce shivering, and, if the patient was conscious and complaining of cold, pethidine was given. Consciousness was regained at low temperature in cases where brain damage had been minimal and anaesthesia had been light; one patient was capable of answering questions at $29.5^{\circ} \mathrm{C}$.

The rate of temperature rise post-operatively gave an indication of the neurosurgical state of the patient. If brain damage had been slight there was a rapid rise within a period of three to five hours, but when brain damage had been severe the temperature would take as long as two to three days to reach normal, with little or no shivering occurring. This slow rise in temperature in the very sick was of definite advantage, as the oxygen requirements of the brain remained low for a long period.

\section{Blood Pressure}

The common pattern of the blood pressure is illustrated in Fig. 4. The initial fall after induction of anaesthesia was followed by a rise due to vasoconstriction of the peripheral vessels, as a result of cooling. This was followed by a gradual fall due to diminished cardiac output, which was

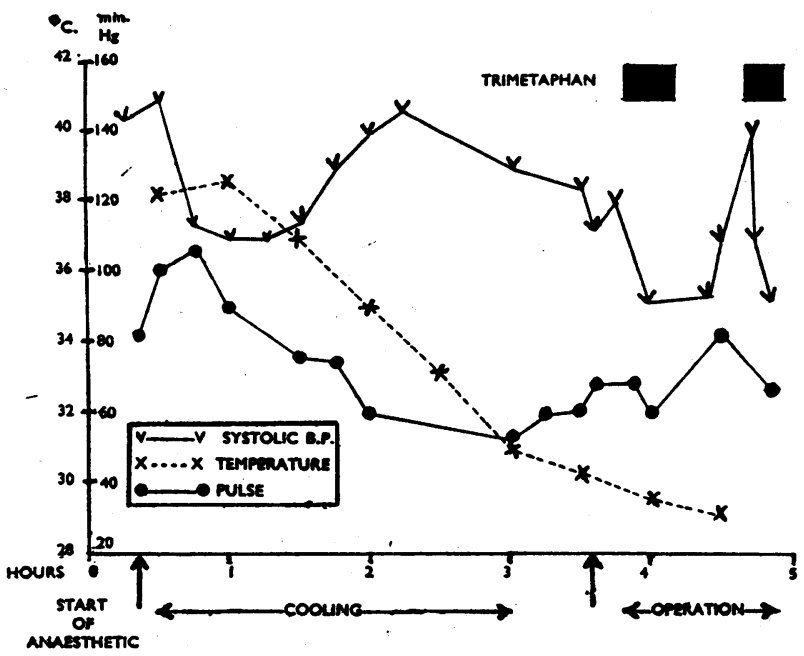

Fig. 4.-Pattern of blood pressure on cooling.

not profound if temperatures were not taken below $30^{\circ} \mathrm{C}$. Bigelow et al. (1950), experimenting with dogs, found a similar pattern in blood pressure on cooling.

With this method of hypothermia, the blood pressure was little disturbed on moving the patient. All operations were carried out with the patient lying with a head-up tilt.

In the first six cases described, this tilting produced falls in blood pressure of between 20 and $80 \mathrm{~mm}$. Hg, whereas using the second method the fall was rarely more than $10 \mathrm{~mm}$. Hg, thus giving greater control over the blood pressure.

This was an advantage, because, although it is safer at low temperatures to lower the pressure due to diminished oxygen requirements (Dundee et al., 1954), it was considered advisable in these cases of brain damage with spasm of the cerebral vessels to limit this low pressure to the shortest time possible.

Thus the blood pressure was lowered only when necessary by using trimetaphan camphorsulphonate ("arfonad").

\section{Trimetaphan Camphorsulphonate}

Operations were performed in nearly all cases at a bloodpressure level of $70-80 \mathrm{~mm}$. Hg. Trimetaphan was given by intravenous infusion at a concentration of $1 \mathrm{mg} . / \mathrm{ml}$. normal saline. In common with other drugs trimetaphan takes longer to act at low temperatures. The sensitivity of patients to this drug varied at low temperatures as at normal temperatures, and consequently time had to be allowed to assess the sensitivity of the patient to the drug by giving it at a very slow drip-rate for three to five minutes. If this was not done a profound drop in blood pressure would occur when the trimetaphan took effect on a sensitive patient. This profound drop in pressure might be prolonged because the compensatory mechanisms for hypotension do not act normally at low temperatures. Prolonged diminished blood supply to the damaged brain might thus occur.

The total amount required to maintain hypotension was found to vary as much in cold patients as in patients at normal temperatures, and large amounts of trimetaphan
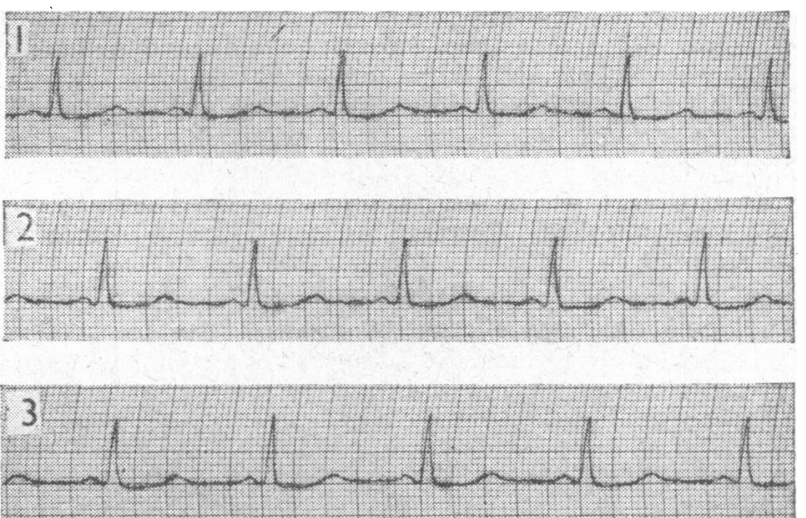

FIG. 5.- Showing effect of trimetaphan. (1) Lead II. Temperature, $30.8^{\circ}$ C.; blood pressure, $95 \mathrm{~mm}$. Hg. (2) Lead II. Temperature, $30.8^{\circ} \mathrm{C}$.; blood pressure, $60 \mathrm{~mm}$. $\mathrm{Hg}$ with trimetaphan. (3) Lead II. Temperature $30.8^{\circ} \mathrm{C}$; ; blood pressure, $60 \mathrm{~mm}$. $\mathrm{Hg}$; trimetaphan discontinued.

(200 mg. or more for a period of one to two hours during operation) might be necessary.

Trimetaphan was given in 74 of the 123 cases, and was effective in all but one of them. In every case there was a slight rise in the pulse rate, usually 10 to 20 per minute, even at temperatures just below $30^{\circ} \mathrm{C}$. In the one resistant case a drop of only $5 \mathrm{~mm}$. Hg could be obtained at a temperature of $29^{\circ} \mathrm{C}$; whereas the pulse rate rose from 48 to 130 a minute and returned to 80 a minute a quarter of an hour after trimetaphan had been discontinued.

It was observed that a fall in blood pressure was difficult to obtain when the brain underwent retraction, and at low temperatures retraction of the brain caused a marked rise in blood pressure when trimetaphan was not being given.

Fig. 5 shows the electrocardiogram at a temperature of $30.8^{\circ} \mathrm{C}$. when trimetaphan was given to lower the blood pressure from 95 to $60 \mathrm{~mm}$. $\mathrm{Hg}$.

\section{Some Findings}

Blood Loss.-At low temperatures patients did not compensate well or quickly for loss of blood. This was shown by the almost immediate drop in pressure, while there was little or no rise in pulse rate. A loss of only $250 \mathrm{ml}$. of blood could cause a severe drop in blood pressure, which did not return to the original level even when blood was replaced. If flattening of the operating table was not effective, small intermittent intravenous injections of noradrenaline, combined with blood replacement, were given to raise the blood pressure.

Pulse.-Increasing bradyeardia occurred as the temperature fell ; usually the rate was below 60 a minute at $30^{\circ} \mathrm{C}$. The lowest value obtained was 36 a minute. Atropine, $0.3-0.4 \mathrm{mg}$., was given intravenously if the rate dropped below 50 a minute. This usually, but not always, caused 
an increase in the pulse rate, which gradually fell again. The cases which did not respond by an increased pulse rate were those in which the sino-auricular node was directly depressed by the effect of cold (Cookson and Di Palma, 1955). Irregularities of the pulse were encountered during cooling, but these remained for only short periods. Moving the patient was the most common cause of these irregularities, which often appeared when transferring the patient from the operating table after anaesthesia had been discontinued: the pulse became regular again after a rise in temperature of a few degrees. Thus moving the patient under light anaesthesia should be avoided. Auscultation of the blood pressure always became difficult as the temperature fell, owing to vasoconstriction of the vessels. The radial pulse could be palpated throughout hypothermia in all but three cases. To reduce the vasospasm in these three cases, a stellate ganglion block was performed at the beginning of the operation, which proved effective in each case. Thus it was possible to keep a record of the systolic blood pressure by palpation of the radial pulse in every case.

Electrocardiographic Control.-The one almost constant finding, apart from lengthening of the whole complex, was the appearance of the "Osborn effect" (Osborn, 1953). This is a secondary wave closely following the $S$ wave-so closely that it appears to be part of the QRS complex. Osborn looked upon this finding as a bad prognostic sign, as it usually preceded fibrillation by about half an hour. G. R. Graham (1957) pointed out that this change in the electrocardiogram under hypothermia is almost constant, and of no serious significance. This was found to be true in this series of cases.

Respirations.-Respirations were controlled, or aided as necessary, with a high flow of gases (4 litres of oxygen to 6 litres of nitrous oxide) without absorption of carbon dioxide. Respirations could not be controlled during operation because their presence and character were a valuable guide to the surgeon. Thus large doses of relaxants for abolishing shivering could not be used. The respiratory rate fell with the temperature in every case. The operation of clipping the anterior cerebral artery in the treatment of anterior cerebral aneurysm at normal temperatures sometimes produces apnoea which appears almost immediately the artery has been occluded. This apnoea was also produced at low temperatures, but might take five to six minutes to appear after the artery had been clipped. One case remained apnoeic for 30 minutes, after which time breathing restarted. Neither this case nor other cases of apnoea from the same cause under hypothermia suffered any lasting ill effect.

\section{Operating Conditions and Selection of Cases}

Haemorrhage from the scalp was usually reduced, but in 5 of the 123 cases haemorrhage was greater than at normal temperatures, and it was concluded that the process of cooling had probably interfered with the effective clotting of blood in these cases. Haemorrhage inside the dura was reduced in all cases, including the five which had increased scalp bleeding.

Intracranial tension was lower than normal in 97 of the cases operated upon, normal in 15 , and raised in 8 . Some of the 97 cases had large intracranial clots, and the tension was low only after these had been removed.

Vascular spasm of the cerebral vessels was present in many of these ruptured intracranial aneurysms at normal temperatures, as demonstrated by the arteriogram. This condition was not abolished by hypothermia, as spasm of these vessels could also be demonstrated at temperatures of $30-31^{\circ} \mathrm{C}$.

Selection of Cases.-Operation took place as soon after admission as possible, and no patient was considered too ill for surgery. Many were already dying from the effects of the haemorrhage they had recently suffered; such cases were classified as category $\mathbf{A}$, and the remaining cases were divided into categories $B$ and $C$ according to the length of time since the last bleed from the aneurysm. There were 29 moribund patients, of whom 16 died in spite of treatment. These cases were unselected both from the neurosurgical and the general condition. Among this series were many chronic hypertensive patients and many with left ventricular hypertrophy and coronary disease. There were two cases of diabetes mellitus and two cases of syphilitic aortitis, one of which had a ruptured aortic valve and was at the time under treatment for cardiac failure.

\section{Post-operative Complications}

Bronchopneumonia was a problem in all cases of continued coma or drowsiness, and particularly if there had been pre-operative signs of chest infection. Antibiotics were given to all cases undergoing hypothermia.

Tracheotomy was performed in every case of continued coma to facilitate suction of secretions from the trachea and bronchi.

There was one case of pulmonary embolus, one of deep calf-vein thrombosis, and one of thrombosis of the long saphenous vein as a result of the intravenous infusion.

Seven cases were reopened post-operatively. In five of these only cerebral oedema was found, and the remaining two cases had subdural haematomata.

Ice was used in packs directly in contact with the skin in 117 cases, and no post-operative damage to the skin occurred in any of these cases.

Summary of Results

The results obtained are shown in Table II. TABLE II

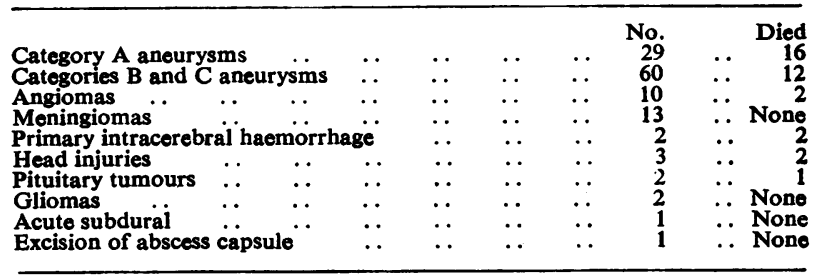

No deaths occurred during the process of hypothermia or during operation. Many of the deaths occurred weeks or even months after operation.

\section{Summary and Conclusions}

The method of producing hypothermia described was evolved from the treatment of 123 cases, 117 of which were treated by surface cooling, using ice, which has the following advantages: (1) it is simple to operate in so far as the minimum of assistance and of complicated equipment are required; (2) control is good, because the time to cool can be predicted; and (3) only a limited number of drugs are necessary.

During the whole of the series no death occurred that was directly attributable to the use of hypothermia, and it is therefore concluded with some certainty that, provided the body temperature is not lowered below $30^{\circ} \mathrm{C}$., the improved operating conditions produced by hypothermia may be obtained at a small increased risk, when compared with the use of a general anaesthetic alone.

In view of this, hypothermia was later used successfully for other intracranial procedures, such as angiomas and meningiomas, where the improved operating conditions were considered to be of value.

This procedure has become routine for all such cases at the Atkinson Morley's Hospital, where this work was undertaken. 
I thank the consultants and all members of the staff of the Atkinson Morley's Hospital for their help and co-operation in conducting this research work, which was made possible by a Research Fellowship awarded by St. George's Hospital.

\section{REFERENCES}

Bigelow, W. G., Lindsay, W. K., and Greenwood, W. F. (1950). Ann. Surg., 132. 849.

- Harrison, R. C., Gordon, R. A., and Greenwood, W. F. (1950). Amer. J. Physiol., 160, 125

Botterell, B. H., Lougheed, W. M., Scott, J. W., and Vandewater, S. L. (1956). J. Neurosurg., 13, 1.

Cookson, B. A., and Di Palma, J. R. (1955). Amer. J. Physiol., 182, 447.

Dundee. J. W., Francis, I. L., and Sedzimir, C. B. (1954). Lancet, 1, 885. Graham. G. R. (1957). Verh. dtsch. Ges. Kreisl.-Forsch., 23, 79.

Lougheed, W. M., Sweet, W. H., White, J. C., and Brewster, W. R. (1955). J. Neurosurg., 12, 240.

McQuiston, W. O. (1949). Anesthesiology, 10, 590.

Osborn, J. J. (1953). Amer. J. Physiol., 175, 389.

Parkhouse. J. (1957). Brit. med. J., 2, 751.

Rosomoff, H. L., and Gilbert, R. (1955). Amer. J. Physiol., 183, 19.

Smith, L. W., and Fay, T. (1939). J. Amer. med. Ass., 113, 653.

\section{PREVENTION OF RHEUMATIC FEVER RECURRENCES}

\author{
BY \\ E. G. L. BYWATERS, M.B., F.R.C.P. \\ AND \\ G. T. THOMAS, M.B., M.R.C.P. \\ From the Rheumatism Research Unit, Canadian Red \\ Cross Memorial Hospital, Taplow, Berkshire, England
}

Sulphonamides were first used in the prevention of rheumatic fever recurrences nearly 20 years ago (Coburn and Moore, 1939 ; Thomas and France, 1939). In 1941, Thomas, France, and Reichsman published their results in a controlled series that had been followed for four years. They found that the frequency of throat cultures positive for Group A haemolytic streptococci was less in a group of 55 patients protected by daily sulphanilamide and that none in this group had had acute streptococcal throat infections or further attacks of rheumatic fever. In the control group (67 patients) there were 15 major attacks of rheumatic fever and four deaths. Rosenberg and Hench (1946) summarized the results of 10 controlled series published between 1939 and 1946, involving over 1,000 personseasons in each of the two groups: the recurrence rate in the protected series was $2.2 \%$ per patient-season and in the unprotected $13.7 \%$.

In 1947 Burke published the first results with penicillin. One group of 10 patients had been given 1,500 Oxford units by mouth daily, and another group of 10 were studied as controls: both had been followed for one year after discharge from hospital. There was a higher incidence of infection of the upper respiratory tract in the unprotected group, and one relapse occurred in this group but none in the protected. There have been many American studies in the past 10 years (summarized by Stollerman, 1954), but only few from this country. Pitt Evans (1950) gave 100,000 units of penicillin daily by mouth to one group of 155 children in a convalescent home; another 145 children were studied as controls. Both groups were followed as inpatients for an average period of 22 weeks. The incidence and duration of the Group A haemolytic streptococcal carrier state was approximately four times greater in the unprotected than in the protected group, and clinical pharyngitis and tonsillitis was over seven times more frequent. There were no relapses of rheumatic fever in the 155 protected patients and four in the 145 unprotected. Gale et al. (1952) observed 73 patients for eight months after discharge from hospital: 41 were given 200,000 units of penicillin daily: the remaining 32 received lactose and glucose. Throat swabs were taken every two weeks. There was a lower incidence of positive throat cultures in the treated group, and, whereas two rheumatic relapses occurred in the 32 controls, there were none in the 41 treated.

Prophylaxis was not used on any large scale in this unit until 1951. We relied instead on isolation (and, if necessary, treatment) of all new admissions until their throat cultures were known to be negative for haemolytic streptococci, and on weekly throat-and-nose swabbing of all patients and staff ; anyone with a positive throat swab was isolated and given intramuscular penicillin. In this way the number of streptococcal infections was kept at a very low level and the recurrences in hospital were few. Experience in this country indicated that recurrences of rheumatic fever after discharge from hospital were much less frequent than had been reported in the U.S.A., where estimates ranging from $40 \%$ per year (Wilson and Lubschez, 1944) down had been reported. Up to 1951, therefore, in view of possible toxic effects from long-continued administration and of the low recurrence risk, our patients had not been put on to prophylaxis on discharge from hospital.

\section{Present Investigation}

In the years 1949 and 1950 there were 96 patients in this unit who were diagnosed as having rheumatic fever; none were put on to prophylaxis in hospital. All fulfilled the criteria for diagnosis of rheumatic fever as defined by Duckett Jones and modified by the American Heart Association (1955). They had, therefore, either two major and one minor, or one major and two minor, criteria (major criteria : polyarthritis, chorea, nodules, erythema marginatum, and carditis ; minor criteria: fever, arthralgia, prolonged $\mathbf{P}-\mathbf{R}$ interval, raised sedimentation rate, evidence of preceding haemolytic streptococcal infection or previous history of rheumatic fever or rheumatic heart disease). Four patients died in hospital. The remaining 92 were not put on to prophylaxis at the time of discharge from hospital. They were seen for follow-up examination at three-monthly intervals for the first year, and thereafter once each year. At each examination a careful history was taken, with special reference to sore throats and limb or joint pains ; a complete physical examination was carried out; and blood was taken for sedimentation rate. All 92 were seen at one year, 91 at two years (1 defaulter), 89 at three years (3 defaulters), 87 at four years (4 defaulters and 1 patient who had died in a recurrence at three years), and 85 at five years ( 2 more defaulters). Thus there were six defaulters by the fifth year and one had died at three years.

In view of the mounting evidence of the efficacy of prophylaxis and the low incidence of toxic reactions, we started to use prophylaxis as a routine measure for both in-patients and out-patients in 1951 as stipulated in the U.S.-U.K. treatment trial in which we were participants (Co-operative

TABLE I.-Comparison Between Protected and Unprotected Groups on First Admission into Hospital

\begin{tabular}{|c|c|c|c|c|c|c|c|c|c|c|c|}
\hline \multirow[t]{2}{*}{ Group } & \multirow[t]{2}{*}{$\begin{array}{l}\text { Total } \\
\text { No. }\end{array}$} & \multicolumn{2}{|c|}{ Sex } & \multicolumn{2}{|c|}{$\begin{array}{c}\text { Age in } \\
\text { Years on } \\
\text { Admission }\end{array}$} & \multicolumn{3}{|c|}{$\begin{array}{l}\text { Degree of } \\
\text { Carditis on } \\
\text { Admission }\end{array}$} & \multicolumn{3}{|c|}{$\begin{array}{c}\text { Duration of } \\
\text { Disease } \\
\text { Activity on } \\
\text { Admission } \\
\text { in Days }\end{array}$} \\
\hline & & $\mathbf{M}$ & $\mathbf{F}$ & $0-10$ & $11-16$ & None & $=\begin{array}{c}\text { Pres. } \\
\text { 1st } \\
\text { Attack }\end{array}$ & $\mid \begin{array}{c}\text { Pres. } \\
\text { 2nd or } \\
\text { Later }\end{array}$ & $2-14$ & $|15-43|$ & $43+$ \\
\hline $\begin{array}{l}1949-50 \\
\text { (un- } \\
\text { protectod) } \\
1951-52 \\
\text { (protected) }\end{array}$ & $\begin{array}{l}96 \\
88\end{array}$ & 53 & 44 & 46 & 50 & 28 & 42 & 26 & 50 & 22 & 24 \\
\hline
\end{tabular}

